\title{
Các yếu tố ảnh hưởng đến nhu cầu học tiếng Anh của sinh viên không chuyên
}

\section{Factors affecting non-English majors' English learning needs}

\author{
Nguyễn Đình Như Hà ${ }^{1}$, Trần Quốc Thao ${ }^{2 *}$ \\ ${ }^{1}$ Trường Cao đẳng Công Thương Thành phố Hồ Chí Minh, Việt Nam \\ ${ }^{2}$ Trường Đại học Công Nghệ Thành phố Hồ Chí Minh, Việt Nam \\ *Tác giả liên hệ, Email: tq.thao@hutech.edu.vn
}

THÔNG TIN

TÓM TẮT

DOI: $10.46223 /$ HCMCOUJS.

soci.vi.15.1.426.2020

Ngày nhận: 03/06/2019

Ngày nhận lại: 17/06/2019

Duyệt đăng: 16/09/2019

Tù khóa:

nhu cầu học tiếng Anh, tiếng

Anh không chuyên, tiếng

Anh chuyên ngành, yếu tố ảnh hưởng đến nhu cầu học tiếng Anh, yếu tố

Keywords:

English learning needs, nonEnglish majors, English for specific purposes, factors affecting English learning needs, factors
Nghiên cứu này nhằm tìm hiểu nhu cầu học tiếng Anh và các yếu tố ảnh hưởng đến nhu cầu học tiếng Anh của sinh viên không chuyên Anh. Một trăm lẻ hai sinh viên đang học năm thứ 2 chuyên ngành Công nghệ thông tin (CNTT) tại một Trường Cao đẳng tại Thành phố Hồ Chí Minh được mời trả lời bảng câu hỏi. Dữ liệu thu thập được xử lý bằng phần mềm SPSS. Kết quả nghiên cứu cho thấy rằng sinh viên chuyên ngành $\mathrm{CNTT}$ có nhu cầu học tiếng Anh khá cao, và các yếu tố như tự học, giảng viên giảng dạy $\mathrm{TACN}$, và môi trường học và tài liệu học tập, và nghề nghiệp tương lai có mối liên hệ tích cực với nhu cầu học tiếng Anh của các sinh viên chuyên ngành CNTT.

\section{ABSTRACT}

This study aims to investigate non-English majors' English learning needs and the factors affecting their English learning needs. This study was conducted with responses from 102 second-year non-English majors at one Ho Chi Minh City college. The data collected from the questionnaires were analyzed by SPSS. The findings indicated that there were fairly high needs for non-English majors. It was also seen that the factors including lecturers, learning autonomy, learning environment and learning materials, and future careers were positively correlated with non-English majors' needs.

\section{1. Đặt vấn đề}

Thế giới đang bước vào thời kì tri thức, xã hội hóa phồn vinh ở thế kỉ XXI phải là một xã hội của tri thức và dựa vào tri thức, vào tư duy sáng tạo của con người. Điều này đòi hỏi người lao động cũng phải biết tự đổi mới kiến thức và năng lực của mình cho phù hợp với sự phát triển của khoa học kĩ thuật và công nghệ. Người lao động phải có khả năng tự định hướng và vươn lên để thích ứng với đòi hỏi của xã hội. 
Trong bối cảnh hội nhập quốc tế và cuộc cách mạng 4.0, sinh viên khối ngành kỹ thuật và công nghệ nước ta có cơ hội được tiếp xúc hàng ngày với những thay đổi nhanh chóng của khoa học và công nghệ. Song song với những thay đổi trong lĩnh vực khoa học và công nghệ, sự hiện diện của tiếng Anh càng đóng vai trò quan trọng hơn. Đặc biệt là tiếng Anh chuyên ngành với hàng loạt thuật ngữ khoa học, với cách diễn đạt rất đa dạng trong các lĩnh vực khoa học kĩ thuật và công nghệ. Như vậy, vai trò của việc dạy và học tiếng Anh chuyên ngành ở các trường Đại học và Cao đẳng trong giai đoạn hiện nay là vô cùng to lớn và mang tính chất quyết định chất lượng của quá trình hội nhập quốc tế. Bên cạnh đó, tiểng Anh sẽ là công cụ mở đường để giúp người học sớm tiếp cận cơ hội làm việc ngay khi vừa mới tốt nghiệp.

Một số nghiên cứu đã chỉ ra việc đào tạo tiếng Anh chuyên ngành (TACN) cho sinh viên nước ta hiện nay chưa hợp lý dẫn đến sinh viên ra trường rất yếu kỹ năng này, ảnh hưởng đến sự phát triển nghề nghiệp (Do \& Cai, 2010; Hoang, 2008). Nỗi lo các doanh nghiệp hiện nay là các $\mathrm{kỹ}$ sư của các Trường Đại học và Cao đẳng ra trường rất yếu tiếng Anh chuyên ngành và chính vì thế dẫn đến sự chậm tiến bộ trong công việc. Hầu hết các doanh nghiệp đều thể hiện quan ngại với khả năng tiếp cận công việc của các kỹ sư sau khi tốt nghiệp, bởi lẽ hầu hết những công việc đòi hỏi tính kỹ thuật đều sử dụng tiếng Anh và đặc biệt tiếng Anh chuyên ngành để phục vụ cho quá trình vận hành và hoạt động sản xuất.

Cũng như các môn học khác, việc lĩnh hội tiếng Anh chuyên ngành của sinh viên không chuyên sẽ là điều kiện giúp các em sớm đạt được công việc và vị trí mong muốn. Sau khi tốt nghiệp, với kiến thức chuyên môn giỏi và vốn tiếng Anh thông thạo, các kỹ sư sẽ dễ dàng chinh phục được các nhà tuyển dụng và tiếp cận công việc trở nên dễ dàng hơn.

Với những vấn đề được đề cập, nghiên cứu này sẽ đi tìm hiểu những yếu tố ảnh hưởng đến việc học tiếng Anh của các sinh viên không chuyên. Nội dung các câu hỏi nghiên cứu sẽ được giải quyết như sau:

1. Nhu cầu học tiếng Anh chuyên ngành của sinh viên không chuyên tại một Trường Cao đẳng ở Thành phố Hồ Chí Minh như thế nào?

2. Những yếu tố ảnh hưởng đến nhu cầu học tiếng Anh chuyên ngành của sinh viên không chuyên tại một Trường Cao đẳng ở Thành phố Hồ Chí Minh là gì?

3. Các yếu tố ảnh hưởng có mối liên hệ với nhu cầu học tiếng Anh chuyên ngành của sinh viên không chuyên như thế nào?

\section{Cổ sở lý thuyết}

Trong phần này tác giả sẽ trình bày các vấn đề liên quan đến đề tài nghiên cứu: nhu cầu học tập và các yếu tố liên quan đến nhu cầu học tập; và trình bày đến các yếu tố ảnh hưởng đến nhu cầu học tiếng Anh chuyên ngành của sinh viên.

\subsection{Nhu cầu học tập}

Nhu cầu học tập là một trong những nhu cầu tinh thần đặc trưng của con người. Nhu cầu học tập là đòi hỏi và nhu cầu thiết yếu của người học nhằm lĩnh hội kiến thức, tri thức và những trải nghiệm thực tế có giá trị của những thế hệ đi trước để lại.

Trong học thuyết nhu cầu Maslow (1970, as cited by Cherry, 2018) chỉ ra nội dung về nhu cầu của con người bao gồm: nhu cầu cơ bản và nhu cầu bậc cao. Maslow cho rằng con người luôn đấu tranh và nỗ lực để thỏa mãn những nhu cầu khác nhau. Những nhu cầu cơ bản 
được ưu tiên chú trọng trước vì chúng sẽ là nguồn định hướng quan trọng để đạt được nhu cầu cao hơn.

Trong mối liên hệ với nhu cầu học tiếng Anh của sinh viên không chuyên, việc học TACN được xem như là nhu cầu cơ bản và thiết yếu bởi lẽ các sinh viên đều có nhu cầu tìm kiếm được công việc tốt trong tương lai và được thể hiện năng lực ngoại ngữ của cá nhân song song với kiến thức chuyên ngành. Tác giả McLeod (2007) cho rằng chỉ khi những nhu cầu cơ bản được thỏa mãn thì người ta sẽ có thể đạt đến thang nhu cầu cao hơn và nhu cầu đó được gọi là nhu cầu tự thể hiện bản thân. Đặc biệt, trong thời đại công nghiệp 4.0, vốn TACN vững chắc sẽ giúp người học khẳng định được bản thân trong môi trường làm việc hơn.

Mỗi người học cũng cần có những mục tiêu để đi đến và nhu cầu mong muốn để đạt được như: nhu cầu được hiểu và được thỏa mãn nội dung học tập, được học trong môi trường đầy đủ tiện nghi, được phát biểu những kiến thức chuyên ngành bằng chính tư duy và sự hiểu biết bản thân, được tự khám phá và tìm hiểu kiến thức, được sử dụng kiến thức đã học vào công việc tương lai.

Trong bối cảnh nghiên cứu này, tác giả xây dựng mô hình các yếu tố ảnh hưởng đến nhu cầu học tiếng Anh của sinh viên. Từ thực tế công tác giảng dạy và phỏng vấn thực tế tại các lớp học. Tác giả sẽ chú trọng phân tích và tìm hiểu mối liên hệ giữa các yểu tố: giảng viên giảng dạy $\mathrm{TACN}$, môi trường học và tài liệu học tập, việc tự học và nghề nghiệp tương lai với nhu cầu học tiếng Anh của sinh viên không chuyên.

\subsection{Các yếu tố ảnh huởng đến nhu cầu học tiếng Anh chuyên ngành của sinh viên}

\section{Giảng viên giảng dạy tiếng Anh chuyên ngành}

Năng lực và phẩm chất nhân cách của người giáo viên giảng dạy TACN chính là "tài" và "đức" và được thể hiện thông qua các giá trị về: lối sống, lập trường chính trị, xã hội, cái nhìn về nhân sinh quan, thế giới quan, thái độ và đặc biệt kiến thức vững chắc về chuyên ngành đang giảng dạy Goonetilleke (1989).

Giáo viên giảng dạy $\mathrm{TACN}$ cần thiết phải có sự chuẩn bị thấu đáo về việc giảng dạy các lý thuyết, hiểu được mong đợi của người học và nắm bắt được sự thay đổi liên tục của công nghệ (Madhavilantha, 2014, p. 7). Theo tác giả Goonetilleke (1989) đề cập rằng "không dễ dàng để tìm kiếm được một giáo viên chuyên ngành hiểu biết tốt lĩnh vực của người học" ( $\mathrm{p}$. 45).

Tuy nhiên một số thực tế về đội ngũ giáo viên giảng dạy tiếng Anh chuyên ngành vẫn còn nhiều bất cập. Theo tác giả Do và Cai (2010) phần lớn giáo viên chuyên ngành là những người có kiến thức chuyên môn giỏi nhưng chưa được tập huấn về phương pháp giảng dạy ngoại ngữ. Milevica (2006) cho rằng giáo viên giảng dạy $\mathrm{TACN}$ vừa phải là một giáo viên giảng dạy tiếng Anh tốt vừa là một chuyên gia trong lĩnh vực đảm nhận.

Giáo viên giảng dạy TACN có những vai trò khác nhau (Swales, 1988) trong đó phải đề cập đến vai trò của Nhà giáo dục. Những giáo viên giảng dạy TACN phải thường xuyên cập nhật thông tin đến các lĩnh vực chuyên ngành cả về tiếng Anh, và chuyên ngành giảng dạy, có phương pháp sư phạm hợp lý trong việc kiểm tra, đánh giá người học và đặc biệt xử lý tốt các tình huống sư phạm xảy ra trong lớp học.

\section{Môi truờng học và tài liệu học tập}

Môi trường học và tài liệu học tập đóng góp một phần quan trọng trong việc lĩnh hội 
kiến thức của người học. Môi trường học tập là những yếu tố bên trong và bên ngoài lớp học có thể ảnh hưởng đến việc tiếp nhận kiến thức của người học. Môi trường học tập vì thế cực kì quan trọng đối với giáo viên và sinh viên. Bởi lẽ, môi trường học tập ảnh hưởng đến cách người dạy truyền đạt kiến thức như thế nào và người học tiếp nhận kiến thức ra sao. Theo DudleyEvans và John (1998) các môi trường học tập TACN phải thể hiện được lĩnh vực chuyên ngành của người học. Việc trang bị các thiết bị dạy học, sử dụng đường truyền kết nối Internet, hệ thống âm thanh lớp học và các hình ảnh trực quan không thể thiếu trong các lớp học TACN.

Bên cạnh đó tài liệu học tập phục vụ cho việc giảng dạy TACN đóng vai trò cũng rất cần thiết. "Tài liệu học tập là bất cứ điều gì có thể sử dụng để giúp giảng dạy. Đó có thể là giáo trình, sách bài tập, $\mathrm{CD}$, các tạp chí, sách báo và hình ảnh, đoạn văn bản được viết trên bảng mà thể hiện nội dung bài học" (Tomlinson, 2011). Đối với sinh viên chuyên ngành tài liệu TACN phải luôn được cập nhật thường xuyên để theo kịp với những xu thế và công nghệ mới.

\section{Yếu tố tụ học}

Yếu tố tự học xuất phát từ những nhu cầu cần lĩnh hội kiến thức của người học, như Knowles (1975) mô tả "Tự học là một quá trình mà người học tự lĩnh hội kiến thức mà không có sự trợ giúp của người khác, họ tự xác định nhu cầu, hình thành mục tiêu, xác định nguồn tài liệu học tập, xây dựng chiến lược học tập và tự đánh giá kết quả học tập.” Theo Knowles (1975), có 3 lý do cho việc tự học như sau: tự học giúp người học nhanh tiếp thu kiến thức, tự học là bản năng vốn có của người học và tự học là cần thiết vì kiến thức luôn thay đổi và phát triển từng ngày.

Trong định nghĩa của Little (1991), yếu tố tự học được xem như khả năng tự chủ kiến thức, phản ánh vấn đề, đưa ra quyết định và hành động độc lập. Trong việc học TACN, người học cần phải có khả năng hoạt động động độc lập, tự tìm hiểu và đánh giá tài liệu chuyên ngành mà không cần sự trợ giúp của giáo viên.

Như vậy, chúng ta có thể thấy rằng nếu người học có cái nhìn đúng đắn về việc tự học và tự lĩnh hội kiến thức thì việc tiếp thu và nâng cao khả năng tiếng Anh chuyên ngành sẽ trở nên dễ dàng hơn.

\section{Yếu tố nghề nghiệp tương lai}

Nghề nghiệp ổn định là sự kỳ vọng của hầu hết các sinh viên khi ra trường. Tuy nhiên trong thực tế tỉ lệ thất nghiệp của sinh viên vẫn còn đang là vấn đề nan giải cho các nhà quản lý. Ngày 24/12/2015, Bộ Lao động - Thương binh và Xã hội cho biết tính đến quý 3 của năm 2015 cả nước có 1 triệu 130 ngàn người ở độ tuổi lao động bị thất nghiệp.

Bên cạnh đó, để cạnh tranh tốt trong thời đại công nghiệp 4.0 ngoài kiến thức chuyên ngành sinh viền phải đạt được những kỹ năng cần thiết khác để có thể làm việc tốt và tìm kiếm được cơ hội việc làm phù hợp. Trong đó tiếng Anh là công cụ hiệu quả giúp sinh viên dễ dàng tìm kiếm công việc trong hầu hết các loại hình doanh nghiệp. Luu (2008) tiến hành một nghiên cứu về nhu cầu học tiếng Anh chuyên ngành điện - điện tử tại Trường Cao đẳng công nghiệp Huế với kết quả 76,6\% sinh viên khi được hỏi về mục đích học tiếng Anh chuyên ngành, họ đều có câu trả lời là để giao tiếp tại nơi làm việc. Nguyen và cộng sự (2016) tiến hành khảo sát vai trò tiếng Anh trong công việc tương lai, có $97 \%$ sinh viên đánh giá rất quan trọng.

\subsection{Lịch sử nghiên cứu}

Trong bài nghiên cứu nhu cầu học tiếng Anh chuyên ngành của sinh viên chuyên ngành 
Du lịch tại Trường Đại học Constanta, Lavinia (2017) đã chỉ ra rằng có 92.6\% sinh viên học tiếng Anh để phục vụ cho nghề nghiệp tương lai. Các sinh viên được khảo sát cho thấy rằng họ nhận thức rõ về sự cần thiết phải phát triển kĩ năng tiếng Anh để đáp ứng nhu cầu của thị trường lao động. Trong bài nghiên cứu về động cơ học tập tiếng Anh của Navickienè, Kavaliauskienè, và Pevcevičiūtè (2015) về động cơ học tiếng Anh - cụ thể tiếng Anh chuyên ngành tại trường Đại học Klaipeda, tác giả đã khảo sát được có đến $95 \%$ sinh viên học tiếng Anh chuyên ngành vì nó cần thiết cho sự nghiệp tương lai và nâng cao trình độ.

Lan, Khaun, và Singh (2011) đã tiến hành nghiên cứu về việc xác định năng lực và kĩ năng ngôn ngữ mà các sinh viên đại học cần phải đáp ứng tại công sở. Kết quả nghiên cứu cho thấy rằng tiếng Anh được sử dụng rộng rãi tại các cơ quan làm việc vì hầu hết các nhiệm vụ cụ thể được thực hiện hầu hết bằng tiếng Anh.

Các khóa học tiếng Anh chuyên ngành giúp người học định hướng được các kĩ năng tiếng Anh cần thiết cho nghề nghiệp tương lai mà người học sẽ gặp phải trong môi trường làm việc. Widdowson (1998) khẳng định rằng "Tiếng Anh tổng quát thiếu tính cụ thể và thiếu mục đích hơn tiếng Anh chuyên ngành." Bởi lẽ tiếng Anh tổng quát chỉ giúp người học tiếp cận những kiến thức cơ bản nhất trong tiếng Anh, trong khi đó tiếng Anh chuyên ngành sẽ giúp người học sớm đạt được vị trí làm việc ổn định hơn với năng lực và kĩ năng ngoại ngữ của mình.

Chính vì thế, việc xác định mục đích học tập cụ thể cũng như tìm kiếm công việc tương lai ổn định, được sử dụng và trau dồi tiếng Anh thường xuyên trong công việc sẽ giúp người học có động cơ học tập đúng đắn hơn. Bên cạnh đó nhận thức tầm quan trọng về TACN sẽ giúp người học chuẩn bị tốt cho các vị trí làm việc đòi hỏi sử dụng tiếng Anh sau này.

\section{Phương pháp nghiên cứu}

\subsection{Nơi nghiên cúu}

Nghiên cứu này được thực hiện tại một Trường Cao đẳng ở Thành phố Hồ Chí Minh trực thuộc Bộ Công Thương và trường được thành lập năm 1976. Số lượng chỉ tiêu tuyển sinh hàng năm của Trường là 4,300 sinh viên, với 10 khoa đào tạo chuyên ngành: Ngoại ngữ, Kế toán - tài chính, Quản trị kinh doanh, Cơ khí, Cơ khí động lực, Điện - điện tử, Công nghệ thông tin, Công nghệ hóa học và thực phẩm, Dệt may, và Da giày.

Trong thời gian 3 năm học tại Trường, các sinh viên khối ngành kinh tế và kĩ thuật được học 3 học phần Anh văn căn bản và 1 học phần tiếng Anh chuyên ngành. Khoa Ngoại ngữ phụ trách đảm nhận giảng dạy học phần tiếng Anh căn bản và tiếng Anh chuyên ngành. Học phần TACN được giảng dạy vào học kì 2 của năm thứ 2 với thời lượng giảng dạy là 30 tiết.

\section{2. Đối tự̛ng khảo sát}

102 sinh viên được phát bảng hỏi nghiên cứu về các yếu tố ảnh hưởng đến nhu cầu học tiếng Anh chuyên ngành. Đối tượng khảo sát là các sinh viên năm thứ 2 đang theo học các lớp tiếng Anh chuyên ngành Tin. Tá́t cả sinh viên đều đã hoàn thành chương trình tiếng Anh phổ thông 7 năm (từ lớp 6 - 12), trong đó có $67.3 \%$ sinh viên đang ở trình độ Trung cấp và $32.7 \%$ sinh viên có trình độ Sơ cấp. Bên cạnh đó tác giả cũng dựa vào điểm tổng kết các học phần Anh văn căn bản để đánh giá rõ hơn về trình độ tiếng Anh của các sinh viên, có đến $41.7 \%$ sinh viên có thang điểm tổng kết từ $5.0-6.0,45 \%$ sinh viên có thang điểm tổng kết từ $6.0-7.0$ và $13.3 \%$ sinh viên có thang điểm tổng kết trên 7.0. 


\subsection{Công cụ nghiên cứu}

Bảng câu hỏi được thiết kế dựa theo mục đích nghiên cứu bao gồm 2 phần: phần 1 là những câu hỏi về thông tin của đối tượng nghiên cứu và phần 2 là các câu hỏi liên quan đến các yếu tố ảnh hưởng đến nhu cầu học tiếng Anh của sinh viên không chuyên. Nó gồm 36 câu theo 5 mức độ từ hoàn toàn không đồng $y$ đến hoàn toàn đồng $y$ và được chia thành 5 nhóm câu hỏi. Bảng 1 cho thấy hệ số Cronbach's Alpha của bảng hỏi thiết lập được sử dụng trong trường hợp nghiên cứu này từ mức .75 trở lên. Điều này có nghĩa là bảng câu hỏi có độ tin cậy cao.

\section{Bảng 1}

Hệ số Cronbach’s Alpha của bảng hỏi nghiên cứu

\begin{tabular}{|l|c|c|}
\hline & Số lượng câu hỏi & Cronbach's Alpha \\
\hline Nhu cầu học TACN & 7 & .75 \\
\hline Giảng viên giảng dạy TACN & 10 & .87 \\
\hline Môi trường học và tài liệu học tập & 6 & .88 \\
\hline Tự học của sinh viên & 7 & .61 \\
\hline Nghề nghiệp tương lai & 6 & .84 \\
\hline
\end{tabular}

Nguồn: Kết quả phân tích dữ liệu của nhóm nghiên cứu

\subsection{Phuơng pháp lấy dũ liệu và tích dũ liệu}

Để thu thập dữ liệu, bảng hỏi được phát đến các sinh viên đang theo học tại lớp tiếng Anh chuyên ngành Tin trong khoảng thời gian 2 tuần. Sinh viên có 15 phút đầu giờ học để đọc và đưa ra lựa chọn phù hợp cho từng thông tin được hỏi.

Dữ liệu sau khi thu thập được xử lý bằng phần mềm SPSS (phần mềm thống kê phân tích dữ liệu) phiên bản 22. Chỉ số trung bình được phân tích theo: hoàn toàn không đồng ý (1.00 - 1.80); không đồng ý (1.81 - 2.60); không ý kiến (2.61 - 3.40); đồng ý (3.41 - 4.20) và hoàn toàn đồng ý $(4.21-5.00)$.

\section{Kết quả và bàn luận}

\subsection{Kết quả}

4.1.1. Nhu cầu học tiếng Anh của sinh chuyên chuyên ngành CNTT

Theo Bảng 2 cho thấy chỉ số trung bình của nhu cầu học tiếng Anh của sinh viên chuyên ngành CNTT là $3.67(\mathrm{~S} . \mathrm{D}=.60)$. Điều này có nghĩa là sinh viên chuyên ngành CNTT có nhu cầu học tiếng Anh khá cao.

\section{Bảng 2}

Chỉ số trung bình của nhu cầu học tiếng Anh của $\mathrm{SV}$ chuyên ngành CNTT

\begin{tabular}{|c|c|c|}
\hline \multirow{2}{*}{} & \multicolumn{2}{|c|}{$\mathbf{N = 1 2 0}$} \\
\cline { 2 - 3 } & $\mathbf{M}$ & S.D. \\
\hline Nhu cầu học tiếng Anh & 3.67 & .60 \\
\hline
\end{tabular}

Trong đó: N: tổng số; M: Trung bình; S.D: Độ lệch chuẩn Nguồn: Kết quả xử lý từ dữ liệu điều tra 
Cụ thể, kết quả khảo sát ở Bảng 3 đề cập về nhu cầu học tiếng Anh của sinh viên chuyên ngành CNTT, sắp sỉ 3/4 (câu 1.6: 74.5\%) sinh viên cho rằng nhu cầu học $\mathrm{TACN}$ vì muốn cập nhật các tài liệu bằng tiếng Anh và có đến $67.6 \%$ (câu 1.5 ) sinh viên muốn giao tiếp thường xuyên bằng tiếng Anh với giáo viên chuyên ngành và $72.5 \%$ (câu 1.1) muốn sử dụng tiếng Anh trong công việc tương lai. Điều đó cho thấy các em đã xác định rõ nhu cầu học tập đúng đắn của bản thân đối với việc học TACN.

Bên cạnh đó các sinh viên cũng đã thể hiện được quan điểm không đồng ý ở mức độ rất thấp khi được hỏi về nhu cầu sử dụng tiếng Anh để tìm kiếm công việc lương cao và muốn sử dụng tốt các kỹ năng tiếng Anh ( $8.9 \%$, câu 1.3 và 1.4$)$. Đây là một tín hiệu đáng quan tâm bởi lẽ các em đã nhận thức được việc trau dồi kiến thức tiếng Anh của bản thân cho các công việc tương lai sau này.

\section{Bảng 3}

Mức độ đồng ý về nhu cầu học tiếng Anh của SV chuyên ngành CNTT

\begin{tabular}{|l|c|c|c|c|c|}
\hline \multicolumn{1}{|c|}{ Nội dung } & \multicolumn{5}{|c|}{ Mức độ đồng ý (\%) } \\
(N=102)
\end{tabular}

Trong đó: 1. Hoàn toàn không đồng ý; 2. Không đồng ý; 3. Không ý kiến; 4. Đồng ý; 5. Hoàn toàn đồng ý Nguồn: Kết quả phân tích dữ liệu của nhóm nghiên cứu

\subsubsection{Yếu tố ảnh huởng đến nhu cầu học tiếng Anh của SV chuyên ngành CNTT}

Kết quả khảo sát ở Bảng 4 cho thấy tổng chỉ số trung bình của các yếu tố ảnh hưởng đến nhu cầu học tiếng Anh của sinh viên không chuyên là 3.47 ( $\mathrm{S} . \mathrm{D}=.65)$. Trong đó, chỉ số trung bình của yếu tố tư học là thấp nhất $(\mathrm{M}=3.01 ; \mathrm{S} . \mathrm{D}=.42)$, điều này cho thấy sinh viên không có ý kiến khi được hỏi về việc tự học của bản thân. Các chỉ số trung bình của những yếu tố: giảng viên giảng dạy $\mathrm{TACN}(\mathrm{GV})(\mathrm{M}=3.52 ; \mathrm{S} . \mathrm{D}=.66$, môi truờng họ và tài liệu học tập (MTTL) $(\mathrm{M}=3.63 ; \mathrm{S} . \mathrm{D}=.78)$, yếu tố nghề nghiệp $(\mathrm{NN})(\mathrm{M}=3.52 ; \mathrm{S} . \mathrm{D}=.73)$ cũng cho thấy rằng sinh viên đồng ý với nội dung được hỏi trong từng yếu tố ảnh hưởng đến nhu cầu học $\mathrm{TACN}$. Điều này có thể hiểu rằng nhu cầu học tiếng Anh của $\mathrm{SV}$ chuyên ngành $\mathrm{CNTT}$ bị ảnh hưởng bởi các yếu tố như giảng viên giảng dạy TACN, môi trương học và tài liệu học tập, và nghề nghiẹp 
tương lai. Tuy nhiên, yếu tố tụ học không có tác động lớn đến nhu cầu học tiếng Anh của sinh viên.

\section{Bảng 4}

Chỉ số trung bình của các yếu tố ảnh hưởng đến nhu cầu học tiếng Anh

\begin{tabular}{|l|c|c|}
\hline \multirow{2}{*}{$\begin{array}{l}\text { Các yếu tố ảnh hưởng đến nhu cầu học tiếng Anh } \\
\text { không chuyên }\end{array}$} & $\mathbf{M}$ & $\mathbf{2}$ \\
\cline { 2 - 3 } Tự học & 3.01 & .42 \\
\hline Gảng viên giảng dạy TACN & 3.52 & .66 \\
\hline Môi trường học và tài liệu học tập & 3.63 & .78 \\
\hline Nghề nghiệp & 3.52 & .73 \\
\hline Tổng & $\mathbf{3 . 4 2}$ & $\mathbf{. 6 5}$ \\
\hline
\end{tabular}

Nguồn: Kết quả xử lý từ dữ liệu điều tra

Kết quả từ Bảng 5 thể hiện mức độ đồng ý của sinh viên giảng dạy tiếng Anh CNTT. Trong đó, một số vấn đề có mức độ đồng ý cao như là $66.7 \%$ (câu 2.4) sinh viên đồng ý với việc giao bài tập tại lớp và về nhà vừa sức với trình độ của sinh viên, $61.8 \%$ (câu 2.10 ) đồng ý việc giáo viên tổ chức thường xuyên các buổi dã ngoại để luyện tập TACN và $58.8 \%$ (câu 2.7 ) đồng ý với việc giáo viên đảm bảo được số giờ dạy theo lịch trình. Điều này thể hiện rõ được nhận thức của sinh viên về tầm quan trọng của giáo viên đối với nhu cầu học TACN. Tuy nhiên, bên cạnh đó cần phải quan tâm đến $33.4 \%$ (câu 2.1) sinh viên không có ý kiến về việc giáo viên thường xuyên cập nhật thông tin và kiến thức chuyên ngành cho bài học. Điều này cũng sẽ là yếu tố làm giảm nhu cầu học TACN của sinh viên nếu sinh viên không thỏa mãn được kiến thức chuyên ngành cần thiết.

\section{Bảng 5}

Mức độ đồng ý của sinh viên về yếu tố giảng viên giảng dạy TACN

\begin{tabular}{|l|c|c|c|c|c|}
\hline \multicolumn{1}{|c|}{ Nội dung } & \multicolumn{5}{|c|}{ Mức độ đồng ý (\%) } \\
(N=102)
\end{tabular}




\begin{tabular}{|l|l|l|l|l|l|}
\hline \multicolumn{1}{|c|}{ Nội dung } & \multicolumn{5}{|c|}{ Mức độ đồng ý (\%) } \\
(N=102)
\end{tabular}

Nguồn: Kết quả phân tích dữ liệu của nhóm nghiên cứu

Kết quả từ Bảng 6 cho thấy mức độ phần trăm đồng ý của sinh viên về yếu tố môi trường học và tài liệu học tập. Đa số kết quả khảo sát đều thể hiện thái độ đích cực của sinh viên với các vấn đề như đội ngũ nhân viên thư viện của trường hố trợ rất tốt cho việc tìm kiếm tài liệu học tập (câu 3.2: 74.5\%), hệ thống internet của Trường đảm bảo được việc tìm kiếm tài liệu học chuyên ngành (câu 3.3: 70.5\%), bên cạnh đó là mức độ đồng ý tương đối cao ở các nội dung đánh giá về phòng học và trang thiết bị (câu $3.5: 69.6 \%$ ) và sĩ số lớp học hợp lý (câu 3.6: $68.6 \%$ ). Có thể nhận thấy được từ kết quả nghiên cứu, các sinh viên chuyên ngành CNTT đều nhận thức rõ tầm ảnh hưởng của yếu tố môi trường học và tài liệu học tập với nhu cầu học TACN.

\section{Bảng 6}

Mức độ đồng ý của sinh viên về yếu tố môi trường học và tài liệu học tập

\begin{tabular}{|l|c|c|c|c|c|}
\hline \multicolumn{1}{|c|}{ Nội dung } & \multicolumn{5}{|c|}{ Mức độ đồng ý (\%) } \\
(N=102)
\end{tabular}

Nguồn: Kết quả phân tích dữ liệu của nhóm nghiên cứu

Kết quả về yếu tố tự học trong Bảng 7 , có $56.9 \%$ (câu 4.1) sinh viên đồng ý việc làm bài tập về nhà và chuẩn bị tốt các buổi thuyết trình; $58.8 \%$ (câu 4.2 ) tham gia các hoạt động nhóm để chuẩn bị cho các bài tập và tỉ lệ phần trăm các em dành 30 phút mỗi ngày học tiểng 
Anh tương đối cao có đến 55.9\% (câu 4.3). Tuy nhiên, một vấn đề bất cập là chỉ có (câu 4.6: $14.7 \%$ ) sinh viên cập nhật giáo trình tiếng Anh chuyên ngành nổi bật và mặc dù hệ thống internet của Trường tương đối ổn định nhưng chỉ có (câu 4.7: 10.8\%) sinh viên sử dụng để làm các bài tập và học tiếng Anh online. Có thể suy ra được mặc dù các em rất chủ động trong việc tự học tuy nhiên các em vẫn chưa có phương pháp học tập phù hợp cho bản thân.

\section{Bảng 7}

Mức độ đồng ý của sinh viên về yếu tố tự học

\begin{tabular}{|l|c|c|c|c|c|}
\hline \multicolumn{1}{|c|}{ Nội dung } & \multicolumn{4}{c|}{ Mức độ đồng ý (\%) } \\
\hline \multicolumn{1}{|c|}{ T=102) } \\
\hline Tụ̂ học & $\mathbf{1}$ & $\mathbf{2}$ & $\mathbf{3}$ & $\mathbf{4}$ & $\mathbf{5}$ \\
\hline 4.1. Làm bài tập về nhà và chuẩn bị tốt các buổi thuyết trình & 5.9 & 12.7 & 6.9 & 56.9 & 17.6 \\
\hline $\begin{array}{l}\text { 4.2. Tham gia hoạt động học nhóm để chuẩn bị cho các bài } \\
\text { tập }\end{array}$ & 4.9 & 2.9 & 20.7 & 58.8 & 12.7 \\
\hline $\begin{array}{l}\text { 4.3. Dành nhiều thời gian tự học tiếng Anh (>= 30 phút mỗi } \\
\text { ngày) }\end{array}$ & 0 & 3.9 & 28.4 & 55.9 & 11.8 \\
\hline $\begin{array}{l}\text { 4.4. Chuẩn bị các bài học: tra từ mới, luyện tập Nghe trước } \\
\text { khi đến lớp }\end{array}$ & 0 & 8.8 & 41.2 & 42.2 & 7.8 \\
\hline $\begin{array}{l}\text { 4.5. Cập nhật thường xuyên các kiến thức chuyên ngành nổi } \\
\text { bật }\end{array}$ & 23.5 & 45.1 & 20.6 & 9.8 & 1.0 \\
\hline 4.6. Cập nhật giáo trình tiếng Anh chuyên ngành nổi bật & 32.4 & 29.4 & 23.5 & 14.7 & 0 \\
\hline $\begin{array}{l}\text { 4.7. Sử dụng Internet để làm các bài tập và học thêm tiếng } \\
\text { Anh online }\end{array}$ & 31.4 & 43.1 & 14.7 & 10.8 & 0 \\
\hline
\end{tabular}

Nguồn: Kết quả phân tích dữ liệu của nhóm nghiên cứu

Trong yếu tố nghề nghiệp tương lai ở Bảng 8 , các sinh viên nhận thức rõ vai trò của việc học tiếng Anh vì mục đích sử dụng cho công việc tương lai (câu 5.5: 74.5\%) và muốn giao tiếp bằng tiếng Anh trong công việc tương lai (câu 5.6: 70.5\%) và tất cả các nội dung còn lại đều có tỉ lệ phần trăm đồng ý rất cao trên $(50 \%)$ cho thấy được việc sinh viên luôn nhận thức vai trò của tiếng Anh với nghề nghiệp sau này.

\section{Bảng 8}

Mức độ đồng ý của sinh viên về yếu tố nghề nghiệp tương lai

\begin{tabular}{|l|c|c|c|c|c|}
\hline \multicolumn{1}{|c|}{ Nội dung } & \multicolumn{4}{|c|}{ Mức độ đồng ý (\%) } \\
(N=102)
\end{tabular}




\begin{tabular}{|l|c|c|c|c|c|}
\hline \multicolumn{1}{|c|}{ Nội dung } & \multicolumn{4}{|c|}{$\begin{array}{c}\text { Mức độ đồng ý (\%) } \\
\text { (N=102) }\end{array}$} \\
\hline $\begin{array}{l}\text { 5.5. Muốn sử dụng tiếng Anh chuyên ngành vào công } \\
\text { việc }\end{array}$ & 6.9 & 10.8 & 7.8 & 56.9 & 17.6 \\
\hline $\begin{array}{l}\text { 5.6. Muốn giao tiếp bằng tiếng Anh trong công việc } \\
\text { tương lai }\end{array}$ & 5.9 & 3.9 & 19.7 & 57.8 & 12.7 \\
\hline
\end{tabular}

Nguồn: Kết quả phân tích dữ liệu của nhóm nghiên cứu

4.1.3. Mối liên hệ giữa nhu cầu học tiếng Anh và các yếu tố ảnh hưởng nhu cầu học tiếng Anh của sinh viên chuyên ngành CNTT

Kết quả ở Bảng 9 cho thấy nhu cầu học tiếng Anh của sinh viên chuyên ngành CNTT có mối liên hệ tương quan tích cực với các yếu tố ảnh hưởng nhu cầu học tiếng Anh. Cụ thể là hệ số tương quan giữa $n h u$ cầu học tiếng Anh và yếu tố giảng viên giảng dạy TACN là r=.759 $(\mathrm{p}=.000)$; giữa nhu cầu học tiếng Anh và yếu tố môi truờng học và tài liệu học tạp là $\mathrm{r}=.564$ $(\mathrm{p}=.000)$; giữa $n h u$ cầu học tiếng Anh và yếu tố tụ học là $\mathrm{r}=.529(\mathrm{p}=.000)$; và giữa $n h u$ cầu học tiếng Anh và nghề nghiệp tuoong lai là $\mathrm{r}=.501(\mathrm{p}=.000)$. Có thể hiểu rằng nhu cầu học tiếng Anh của sinh viên càng cao thì các yếu tố (giảng viên giảng dạy TACN, môi truờng học và tài liệu học tập, tư học và nghề nghiệp tuoơng lai) ảnh hưởng đến nhu cầu học tiếng Anh càng cao.

\section{Bảng 9}

Mối liên hệ giữa nhu cầu học tiếng Anh và các yếu tố ảnh hưởng nhu cầu học tiếng Anh

\begin{tabular}{llcccc}
\hline & & GV & MTTL & NN & TH \\
\hline Nhu cầu học & Pearson Correlation & .759 & .564 & .529 & .501 \\
tiếng Anh & Sig. (2-tailed) & $.000^{*}$ & $.000^{*}$ & $.000^{*}$ & $.000^{*}$ \\
& $\mathrm{~N}$ & 102 & 102 & 102 & 102 \\
\hline
\end{tabular}

$* \mathrm{p}<.01$

Nguồn: Kết quả xử lý từ dữ liệu điều tra

\subsection{Bàn luận}

Từ kết quả khảo sát cho thấy sinh viên chuyên ngành CNTT đã xác định rõ nhu cầu học tập TACN. Lý giải cho kết quả này có thể là sinh viên đã nhận thức được việc học tập không chỉ để đạt được điểm số yêu cầu mà họ đã nhận thức được vai trò của $\mathrm{TACN}$ với cuộc sống hiện tại và công việc tương lai của bản thân. Như Navickienè và cộng sự (2015), Lavinia (2017) đã chứng minh được nhu cầu học $\mathrm{TACN}$ của sinh viên là phục vụ cho công việc tại môi trường công sở.

Ngoài ra, kết quả còn chỉ ra tầm quan trọng của từng yếu tố ảnh hưởng đến nhu cầu học TACN của sinh viên. Đầu tiên, yếu tố giảng viên giảng dạy tiếng Anh chuyên, trong đó năng lực, trình độ chuyên môn và chuyên ngành giảng dạy, và đảm bảo được khối lượng giảng dạy có sự ảnh hưởng tích cực đến nhu cầu học của các sinh viên. Như quan điểm của Goonetilleke (1989), Madhavilantha (2014) và Swales (1988) cho rằng một giáo viên giảng dạy tiếng Anh chuyên ngành cần thiết vững vàng không chỉ về trình độ tiếng Anh mà cả kiến thức chuyên ngành của sinh viên để kích thích được sự đam mê và đáp ứng nhu cầu năng lực của sinh viên học TACN. Bên cạnh đó, từ quan điểm của Dudley-Evans và John (1998) về môi trường học tập TACN phải thể hiện được lĩnh vực chuyên ngành của người học. Kết quả đã thể hiện rằng đối với các sinh viên việc học trong một môi trường được trang bị đầy đủ thiết bị và những tài 
liệu học tập để phục vụ nhu cầu học tập và nghiên cứu rất cần thiết. Đặc biệt, đối với sinh viên chuyên ngành $\mathrm{CNTT}$, tài liệu nghiên cứu và học tập luôn được cập nhật thường xuyên và luôn phải đáp ứng với sự tiến bộ của công nghệ và kĩ thuật của cả thế giới. Chính vì vậy, để phục vụ cho nhu cầu học tiếng Anh của sinh viên thì không thể thiếu những trang thiết bị cần thiết và đội ngũ nhân viên thư viện có năng lực. Một yếu tố khác ảnh hưởng đến nhu cầu học tập của sinh viên là tự học. Như Knowles (1975) và Little (1991) khẳng định việc tự học giúp xác định được nhu cầu học tập đúng đắn của người học. Kết quả tìm hiểu được rằng sinh viên đã có cái nhìn đúng đắn về việc tự học và cách thức tự học của bản thân, nhưng yếu tố này chưa thực sự ảnh hưởng đến nhu cầu học tiếng Anh của sinh viên CNTT. Từ kết quả nghiên cứu cho thấy rằng sinh viên $\mathrm{CNTT}$ cần phải có những phương pháp học tập đúng đắn hơn cũng như cần tận dụng tối đa các phương tiện hỗ trợ học tập để bổ sung kiến thức cho cá nhân. Ngoài ra sinh viên cần nhận thức rõ vai trò của việc tự học đối với nhu cầu học tiếng Anh của bản thân để tìm ra những phương pháp và cách thức học tiếng Anh tốt nhất. Yếu tố nghề nghiệp cũng có một sự ảnh hưởng đến nhu cầu học tiếng Anh của các sinh viên CNTT. Điều đáng quan tâm từ kết quả nghiên cứu là hầu hết các sinh viên đều xác định nhu cầu học tiếng Anh đúng đắn đó là việc học TACN để phục vụ cho công việc tương lai. Đặc biệt, hầu hết sinh viên đều mong muốn được sử dụng lại chính những kiển thức đã tích lũy và sử dụng thành thạo trong công việc. Điều này phù hợp với nghiên cứu mà tác giả Luu (2008) và Nguyen và cộng sự (2016) đã thực hiện trong việc tìm hiểu nhu cầu học tiếng Anh của sinh viên không chuyên.

Mô hình giả thuyết ban đầu của bài nghiên cứu về các yếu tố ảnh hưởng đến nhu cầu học tiếng Anh của sinh viên không chuyên đã chứng minh được rằng có mối liên hệ tích cực với giảng viên giảng dạy $\mathrm{TACN}$, môi trường học tập và tài liệu học tập, tự học và nghề nghiệp với nhu cầu học tiếng Anh của sinh viên không chuyên. Trong đó yếu tố tự học dù kết quả khẳng định có mối liên hệ với nhu cầu học tiếng $A n h$, tuy nhiên yếu tố này chưa ảnh hưởng lớn đến việc hình thành và xác định nhu cầu học tiếng Anh của sinh viên CNTT $(\mathrm{M}=3.01)$. Kết quả cũng đã khẳng định rằng sinh viên chuyên ngành $\mathrm{CNTT}$ xác định rõ được động cơ và nhu cầu học tiếng Anh chuyên ngành của bản thân. Việc xác định nhu cầu học TACN của sinh viên thể hiện qua những nhu cầu như mong muốn tìm việc làm ổn định, làm việc trong môi trường nước ngoài và sử dụng tốt các kĩ năng tiếng Anh vào công việc tương lai. Hơn thế nữa McLeod (2007) đã đề cập đến việc hình thành thang nhu cầu của mỗi cá nhân, điều này tương đồng với mối liên hệ gắn kết giữa các yếu tố ảnh hưởng với nhu cầu học TACN của sinh viên CNTT. Đó là khi nhu cầu càng cao thì mối liên hệ giữa các yếu tố càng thể hiện rõ nét hơn và các yếu tố này bỗ trợ cho quá trình hình thành nhu cầu đúng đắn của sinh viên trong việc học TACN.

\section{Kết luận}

Từ kết quả nghiên cứu đã chứng minh được rằng hầu hết các sinh viên chuyên ngành CNTT đã xác định được nhu cầu học $\mathrm{TACN}$ đúng đắn. Bản thân của các sinh viên cũng nhận thức rõ được vai trò của các yếu tố giảng viên giảng dạy $\mathrm{TACN}$, môi trường học và tài liệu học tập, tự học và nghề nghiệp đối với việc hình thành nhu cầu học của bản thân. Riêng yếu tố tự học chỉ ra rằng sinh viên cần có những phương pháp tự học tích cực và hiệu quả hơn.

Đồng thời, nghiên cứu này cũng đã chứng minh được mối liên hệ tích cực của các yếu tố ảnh hưởng đến nhu cầu học tiếng Anh của sinh viên không chuyên. Mặc dù các sinh viên vẫn còn có những hạn chế về việc tiếp cận môn học TACN nhưng phải khẳng định rằng kết quả nghiên cứu đã cho thấy các em đã ý thức đầy đủ được vai trò của ngoại ngữ đối với nghề nghiệp tương lai và sự thành công trong công việc sau khi hoàn thành xong chương trình học. 
Bên cạnh đó, kết quả nghiên cứu cũng mang lại những lợi ích như việc giúp những giáo viên giảng dạy $\mathrm{TACN}$ và lãnh đạo Trường có những giải pháp hợp lý để tiếp tục duy trì và nâng cao chất lượng học và dạy môn TACN nói riêng cũng như ngành CNTT nói chung. Mặc dù nghiên cứu vẫn còn một số hạn chế về đối tượng cũng như chưa khái quát hóa đầy đủ các yếu tố ảnh hưởng đến nhu cầu học TACN nhưng những kết quả đạt được sẽ là tiền đề cho các nghiên cứu khác được thực hiện tại Trường và các cơ sở đào tạo khác trong việc đánh giá chất lượng dạy và học tiếng Anh của sinh viên không chuyên.

\section{Tài liệu tham khảo}

Bojovié, M. (2006). Teaching foreign language for specific purposes: Teacher development. Paper presented at the 31st Annual ATEE Conference, Portoroz, Slovenia.

Cherry, K. (2018). How Maslow's famous hierarchy explains human motivation. Retrieved May 15, 2019, from https://www.verywellmind.com/what-is-maslows-hierarchy-ofneeds-4136760

Do, D. T. X., \& Cai, A. N. D. (2010). Dạy và học tiếng Anh chuyên ngành trong tình hình mới: Thách thức và giải pháp [Teaching and learning specialized English in new situation: Challenges and solutions]. Tạp chi Khoa học Đại học Huế, 60, 31-41.

Dudley-Evans, T., \& John, M. J. S. (1998). Developments in ESP: A multi-disciplinary approach. Cambridge, UK: Cambridge University Press.

Goonetilleke, D. C. (1989). Language planning and ESP with special reference to Sri Lanka. In P. W. Peterson (Ed.), ESP in practice (pp. 41-46). Washington, DC: United States Information Agency.

Hoang, V. V. (2008). Những yếu tố Ảnh hưởng đến chất lượng đào tạo tiếng Anh chuyên ngành ở Đại học Quốc gia Hà Nội [Factors affecting the quality of specialized English training at Hanoi National University]. Tạp chí Khoa học Đại học Quốc gia Hà Nội, 24, 22-37.

Javid, Z. C. (2015). English for specific purposes: Role of of learners, teachers and teaching methodologies. European Scientific Journal, 11, 17-34.

Knowles, M. (1975). Self-directed learning. New York, NY: Association Press.

Lan, C. O. T., Khaun, A. L. C., \& Singh, P. K. S. (2011). Employer expectations of language at the workplace. Malaysian Journal of ELT Research, 7(2), 82-103.

Lavinia, N. (2017). ESP teaching and needs analysis. Case study. Economic Sciences Series, $17(2), 268-273$.

Little, D. (1991). Learner autonomy 1: Definitions, issues and problems. Dublin, Ireland: Authentik Language Resources Ltd.

Luu, K. Q. (2008). Khảo sát nhu cầu học đối với chương trình môn học tiếng Anh chuyên ngành cho sinh viên ngành Điện tử trường Cao đẳng Công nghệ Huế [Survey of study needs for specialized English subject programs for electronics students of Hue College of Technology]. Tạp Chí Khoa học và Công nghệ, 4(27), 153-159.

Madhavilantha, B. (2014). Teacher education and ESP. International Journal of Research, Humanities, Arts, and Literature, 2(4), 73-82. 
McLeod, S. (2007). Behaviorist approach. Retrieved May 17, 2019, from http://www.simplypsychology.org/behaviorism.html\#sthash.IFZMW9pB.dpbs

Milevica, B. (2006). Teaching foreign language for specific purposes: Teacher development. Proceedings of 31st Annual ATEE Conference At: Portoroz, Slovenia, 487-493. doi:10.13140/2.1.4011.4566

Navickienè, V., Kavaliauskienè, D., \& Pevcevičiūtè, S. (2015). Aspects of ESP learning motivation in tertiary education. TILTAI, 2, 97-108.

Nguyen, H. T., Ngo, D. T. H., Tran, H. T., Nguyen, B. T., Vu, Q. L., Pham, H. T., ...Nguyen, T. T. (2016). Đề xuất giải pháp nâng cao khả năng sử dụng tiếng Anh cho sinh viên ngành công nghệ chế biến thủy sản: Dựa trên kết quả khảo sát thực tế [Proposing solutions to improve students' ability to use English in seafood processing technology: Based on actual survey results]. In Kỉ yếu hội thảo cấp trường (pp. 94-101). Nha Trang, Vietnam: Trường Đại học Nha Trang.

Swales, J. M. (1988). Episdoes in ESP. Hemel Hempstead, UK: Prentice Hall International Ltd.

Tomlinson, B. (2011). Material development in language teaching. Cambridge, UK: Cambridge University Press.

Widdowson, H. G. (1998). The theory and practice of critical discourse analysis. Applied Linguistics, 19(1), 136-151. 